\title{
Numerical Matching Between Granule and Purkinje Cells in Lurcher Chimeric Mice: A Hypothesis for the Trophic Rescue of Granule Cells from Target-Related Cell Death
}

\author{
Michael W. Vogel, Karen Sunter, and Karl Herrup \\ Department of Human Genetics, Yale Medical School, New Haven, Connecticut 06510
}

\begin{abstract}
Previous studies of wild-type mice or mutant $\leftrightarrow$ wild-type mouse chimeras using the neurological mutant staggerer have supported a numerical matching hypothesis for targetrelated cell death. However, analyses of chimeras of a second neurological mutant, Iurcher, have suggested that there may be significant flexibility in the relationship between the numbers of pre- and postsynaptic neurons. Whereas in staggerer chimeras there is a strict proportionality between the number of cerebellar granule cells and their postsynaptic target, the Purkinje cells, in Iurcher chimeras, Wetts and Herrup (1983) report a relative increase in granule cell survival. We have reexamined the numerical matching between Purkinje and granule cells in an additional 5 lurcher $\leftrightarrow$ wildtype and 4 wild-type $\leftrightarrow$ wild-type chimeras. Our findings confirm and extend the results of the previous study to show that there is a close correlation between the number of granule and Purkinje cells in $+/ L c$ chimeras, but for any given number of Purkinje cells in the $+/$ Lc chimeras, more granule cells survive than in staggerer chimeras or inbred mouse strains. Whereas the ratio of granule to Purkinje cells in staggerer chimeras or inbred mouse strains is constant across all target sizes, in $+/ L C$ chimeras the ratio of granule cells to Purkinje cells increases as the number of target neurons decreases. It seems likely that the increased granule cell survival is somehow related to the delayed degeneration of the $+/ L c$ fraction of target cells in the $+/ L c$ chimeras. Among the possible explanations for the observed results, we favor the hypothesis that a trophic factor is produced in $+/ L c$ chimeras in response to the deafferentation of Purkinje cells that is capable of rescuing granule cells from target-related cell death. Our preference is based, in part, on observations of the state of the dendritic tree of the wild-type Purkinje cells that survive in +/Lcchimeras (Caddy et al., 1986).
\end{abstract}

A recurring theme in the ontogeny of the nervous system is the spontaneous death of neurons as part of the normal develop-

\footnotetext{
Received Oct. 13, 1989; revised Mar. 10, 1989; accepted Mar. 22, 1989.

We would like to thank Jim Soha for his helpful comments and criticisms during the writing of this paper. This research was supported by the NIH (M.W.V., NS07689; K.S. and K.H., NS18381 and NS20591) and the March of Dimes Birth Defects Foundation (Basic Research Grant 1-763).

Correspondence should be addressed to Michael W. Vogel, Maryland Psychiatric Research Center, P.O. Box 21247, Baltimore, MD 21228.

a Present address: Department of Developmental Neurobiology, E. K. Shriver Center, 200 Trapelo Road, Waltham, MA 02254.

Copyright (C) 1989 Society for Neuroscience $0270-6474 / 89 / 103454-09 \$ 02.00 / 0$
}

mental program. While the specific logic of this cell death is unknown, a variety of experimental findings have indicated that some property of the neuronal target plays an important role in its regulation (for recent reviews, see Cowan et al., 1984; Lamb, 1984; Oppenheim, 1985; Williams and Herrup, 1988). Various hypotheses have been proposed to account for this paradoxical loss of neurons and its relationship to the presence of target. It has been suggested that cell death might provide a mechanism to correct for errors of axonal projections or cell position (Lamb, 1979, 1981; O'Leary and Cowan, 1982; Denton et al., 1985). Another commonly invoked model is that cell death serves in numerically matching the size of the pre- and postsynaptic populations. According to this model, presynaptic neurons are originally generated in excess. After they contact their target, the availability of some limited trophic element, such as synaptic sites or a diffusable factor (for review, see Oppenheim, 1985), determines how many of the presynaptic neurons will survive. An implicit prediction of this model is that there should be a simple numerical function that relates presynaptic neuron number to some metric of target size. There is evidence both for and against this model.

Recent experimental findings in both the chick and mouse indicate that the size of the target may regulate the size of the post-cell-death presynaptic neuronal population very precisely (Tanaka and Landmesser, 1986; Herrup and Sunter, 1987; Lanser and Fallon, 1987). The chick experiments provide evidence that alterations in the size of the limb target (through interspecies chimeras or genetic mutation) lead to a linear relationship between motoneuron number and the pre-cell-death number of primary myotubes or muscle mass. The mouse studies indicate that altcrations in the number of Purkinjc ccll targets available during granule cell development in staggerer $\leftrightarrow$ wild-type aggregation chimeras lead to a linear response in the number of presynaptic granule cells that survive the period of target-related cell death. The suggestion from both of these systems is that presynaptic neuronal number may be defined as a simple linear function of the number of postsynaptic targets.

However, several experimental findings have suggested that there is more to the regulation of cell death than numerical matching alone. While experiments designed to increase the relative amount of target do permit more neurons to survive, the extent of this rescue does not match the extent of target increase (Hollyday and Hamburger, 1976; Narayanan and $\mathrm{Na}$ rayanan, 1978; Boydston and Sohal, 1979; Pilar et al., 1980; see also Sohal et al., 1986). The survival of up to $100 \%$ of the normal numbers of motoneurons in bilaterally innervated single 
frog legs (Lamb, 1981) has been taken as further evidence against a causal role for target size per se in regulating the extent of cell death. These studies suggest that there may be other factors beside target size that influence the numerical balance achieved between presynaptic neurons and their target (see also Sperry, 1988).

Analyses of neuron-target interactions between granule and Purkinje cells in the cercbclla of mutant $\leftrightarrow$ wild-type mice(Wetts and Herrup, 1983; Herrup and Sunter, 1987) have produced evidence both for and against a strict linear numerical matching between pre- and postsynaptic populations. The granule cellPurkinje cell circuit of the mouse cerebellum provides a particularly convenient system for the study of neuron-target interactions, especially when analyzed in the context of mutant $\leftrightarrow$ wild-type chimeras. It is relatively easy to quantitate the size of both neuronal populations and, through the use of mutant $\leftrightarrow$ wild-type chimeras, it is possible to vary the size of the Purkinje cell target over a wide range of values. In wild-type mice and in staggerer $(\mathrm{sg} / \mathrm{sg}) \leftrightarrow$ wild-type chimeras, there is a linear relationship between the number of granule cells and the number of wild-type Purkinje cells, and a constant granule cell to Purkinje cell ratio. This indicates that the target tightly regulates the size of the presynaptic population. However, in $+/ L c \leftrightarrow$ wild-type chimeras, Wctts and Herrup (1983) found that the ratio of granule to Purkinje cells varied among chimeras and could be increased 1- to 5-fold over the wild-type ratio of 185 granule cells per Purkinje cell.

The lurcher mutation used in this study is autosomal dominant and causes the intrinsic degeneration of $+/ L c$ Purkinje cells following the first week of postnatal development (Phillips, 1960; Caddy and Biscoe, 1979; Welts and Herrup, 1982a). Although $90 \%$ of the granule cells degenerate in the $+/ L c$ mutant, their death is secondary to the primary action of the gene defect in the $+/ L c$ Purkinje cells (Wetts and Herrup, 1982a, b). Thus, at birth, the cerebella of $+/ L c \leftrightarrow$ wild-type chimeras contain varying proportions of $+/ L c$ and wild-type Purkinje cells; however, the $+/ L c$ Purkinje cells degenerate early in postnatal development, leaving varying numbers of wild-type Purkinje cells scattered throughout the cerebellar hemispheres (Wetts and Herrup, 1983). The purpose of this study was to reexamine the quantitative properties of neuron-target relationships in the granule cell-Purkinje cell circuit of the mouse cerebellum in lurcher $\leftrightarrow$ wild-type chimeras. We did this to determine more precisely how the variation in the numerical matching relationship between pre- and postsynaptic populations observed in Wetts and Herrup's (1983) study of $+/ L c$ chimeras compares with the strict numerical matching of presynaptic neurons with target size observed in studies of both the mouse (Herrup and Sunter, 1987) and the bird (Tanaka and Landmesser, 1986; Lanser and Fallon, 1987). We describe the analysis of 9 additional $+/ L c \leftrightarrow$ wild-type and wild-type $\leftrightarrow$ wild-type chimeras. These data have permitted us to perform a more detailed analysis of the quantitative aspects of neuron-target interactions in the $+/ L c$ chimeric cerebellum. The results indicate that while the Purkinje cell population regulates the size of the granule cell population in the $+/ L c$ chimeras, there is a unique aspect of $+/ L c$ chimeras that allows increased granule cell survival. Among the possible explanations for the observed results, we propose that the data are best explained by the existence of target-derived factors in $+/ L c$ chimeras that support the survival of increased numbers of granule cells. Some of these results have been presented in an abbreviated version elsewhere (Vogel et al., 1987).

\section{Materials and Methods}

Animals. The chimeric mice used in this study were produced according to standard embryo aggregation techniques (Mintz, 1965; Tarkowski, 1961; Mullen and Whitten, 1971) $+/ L c$ chimeric embryos are produced by placing an 8-cell stage embryo from a heterozygote lurcher mating in contact with an 8-cell stage embryo from a wild-type, inbred mouse mating. The embryos are cultured overnight, and any embryos that have succcssfully aggregated to form double-sized morulas are transplanted into pseudopregnant host females. The resulting pups are delivered either naturally or by cesarian section $17 \mathrm{~d}$ later. Heterozygote lurcher embryos were produced from matings of C57BL/6J $-+/ L c$ and $\mathrm{C} 57 \mathrm{BL} / 6 \mathrm{~J}-+1+$ mice, and wild-type embryos were produced from either the inbred strain $\mathrm{C} 3 \mathrm{H} / \mathrm{HEJ}$ or $\mathrm{AKR} / \mathrm{J}$.

Successful chimeras were identified on the basis of their coat color markers and on the results of progeny testing (see Wetts and Herrup, 1983). C57BL/6J-+/Lc and C57BL/6J-+/+ mice are black, while C3H/ $\mathrm{HEJ}$ and AKR/J mice are agouti and albino, respectively. Thus, successful chimeras will have a mix of coat colors. However, since the C57BL/6J-+/Lc embryos were produced by mating C $57 \mathrm{BL} / 6 \mathrm{~J}-+/ L c$ males with $\mathrm{C} 57 \mathrm{BL} / 6 \mathrm{~J}-+1+$ females or vice versa, only $50 \%$ of the embryos produced from these matings are heterozygous for the lurcher allcle. Therefore, successful chimeras identified by the coat color markers were also backcrossed with wild-type mice to look for the production of $+/ L c$ progeny. Since the chimeras could be either $+/ L c \rightarrow$ wild-type or wild-type $\leftrightarrow$ wild-type in genotype, any chimera that produced $+/ L c$ offspring was identified as a $+/ L c \rightarrow$ wild-type chimera.

Histology and cell counts. All animals were killed by cardiac perfusion with either Bouin's fixative or 4\% paraformaldehyde in phosphate buffer $(\mathrm{pH} 7.2)$. The brain was dissected out of the skull, postfixed for up to $6 \mathrm{hr}$, and then rinsed extensively. Each half brain was embedded in wax and serially sectioned at $8 \mu \mathrm{m}$. Every fifth section was stained with cresyl violet and the succeeding serial section was stained for $\beta$-glucuronidase. Sections stained for cresyl violet were used for Purkinje and granule cell counts, while sections stained for $\beta$-glucuronidase were examined for high and low $\beta$-glucuronidase-stained Purkinje cells to confirm the genctic makc-up of the chimeras. C57BL/6J- $+/ L c$ and C57BL/6J- $+/+$ mice contain the high-staining alleles for $\beta$-glucuronidase $\left(G u s^{b} / G u s^{b}\right)$, while $\mathrm{C} 3 \mathrm{H} / \mathrm{HEJ}$ and $\mathrm{AKR} / \mathrm{J}$ mice contain the low-staining alleles ( $G u s^{h} /$ Gush).

Purkinje cells were counted in every 20th or 30th section as described by Wetts and Herrup (1983). Cells counted as Purkinje cells were those cells that were in the Purkinje cell layer, had a large-diameter soma, and had at least a portion of the nucleus in the section. The total number of Purkinje cells in each half brain was calculated from a graph of the number of Purkinje cells in each counted section plotted against the section's distance from the midline. Corrections were made for double counting Purkinje cells based on the methods of Hendry (1976). The Purkinje cells of the additional $+/ L c$ chimeras presented in this paper were counted by one author (K.S.), while the Purkinje cells in control wild-type $\leftrightarrow$ wild-type chimeras were counted by a different author (M.W.V.). Counting errors for multiple counts of the same brain fell within $3 \%$.

The total number of granule cells per half cerebellum was calculated by multiplying the average density of granule cells in the granule cell layer by the volume of the granule cell layer (Wetts and Herrup, 1982b). Granule cell density was determined by counting the number of granule cells within a $20,000 \mu \mathrm{m}^{3}$ grid $(50 \times 50 \times 8 \mu \mathrm{m})$ in selected regions of each half cerebellum. In general, 6-10 cerebellar sections, selected at $240 \mu \mathrm{m}$ intervals along the medial to lateral cerebellar axis, were picked for granule cell counts. In each $8 \mu \mathrm{m}$ cerebellar section, a $50 \times 50 \mu \mathrm{m}$ grid was superimposed over a region of the granule cell layer, and all of the granule cells within the grid were counted. This process was repeated for 4-6 distinct regions within the granule cell layer in each of the 6-10 cerebellar sections that were counted. Thus, the numbers of granule cells in at least twenty-four $20,000 \mu \mathrm{m}^{3}$ grids were counted to determine the average density of granule cells (number of granule cells/ $\mu \mathrm{m}^{3}$ ). The volume of the gramule cell layer was calculated from a graph of granule cell layer area $\left(\mathrm{mm}^{2}\right)$ plotted against distance from the midline (mm). Granule cell layer area was measured by tracing the outline of the granule cell layer through a camera lucida attachment onto a digitized $X-Y$ pad where the area was determined using a semiautomatic image-analysis system (Bioquant, R\&M Biometrics, Inc., Nashville, TN). Granule cell layer areas were measured at $240 \mu \mathrm{m}$ intervals along the medial to lateral axis of the cerebellum and then plotted against distance 

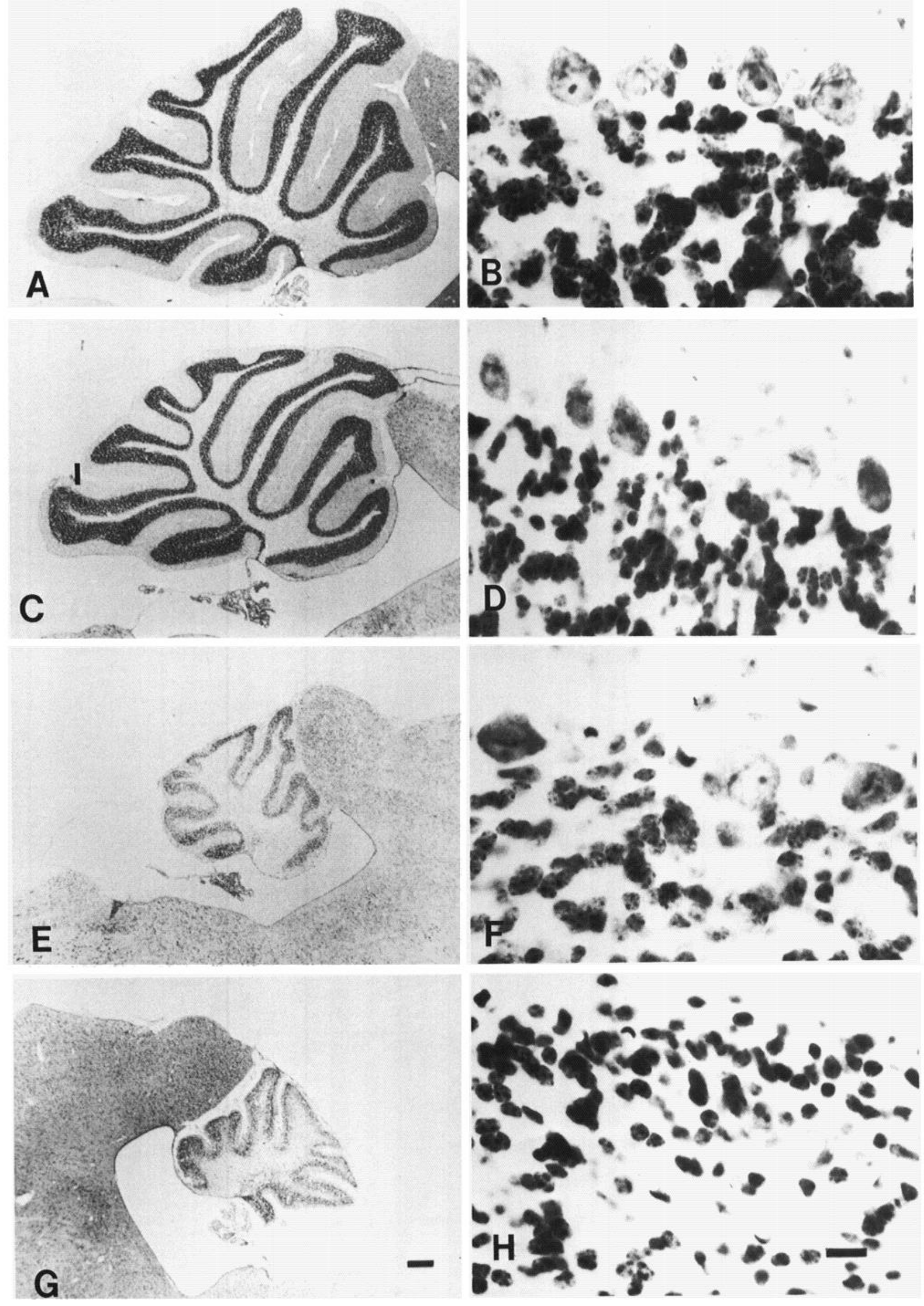
from the midline. The volume of the granule cell layer was calculated from the area under the resulting curve. Corrections for double-counting errors were made using the methods of Hendry (1976). All counts of granule cells were performed by one author (M.W.V.). The counting error for duplicate counts of granule cell regions was within 3-5\%.

Regression analysis of Purkinje and granule cell data was carried out using the Statistical Analysis System (SAS) statistics package. Separate regression equations were calculated for the lurcher chimeras and control animals (inbred strains and wild-type $\leftrightarrow$ wild-type chimeras) to evaluate how well the separate data sets fit either straight-line or curvilinear equations. To test for colinearity of the data sets for the linear models, a combined linear-regression equation was calculated that included experimental treatment (lurcher chimera or control animal) as a classification variable (Berenson et al., 1983). The partial $F$ test for parallelism was calculated for the linear-regression equations to determine if the slopes for the lurcher chimera and control animal equations are parallel, and analysis of covariance was used to determine if the differences between the lurcher chimera and control animal data were significant.

\section{Results}

\section{Qualitative observations}

The degeneration of $+/ L c$ Purkinje cells early in postnatal cerebellar development in $+/ L c \leftrightarrow$ wild-type chimeras does not dramatically alter the neuronal cytoarchitecture of the chimeric cerebellum, as revealed by Nissl staining. The size of the chimeric cerebellum is often reduced in volume compared with wild type, but the characteristic organization of the cerebellar cell layers is not disturbed (see Fig. 1). A sagittal section of a cerebellum from a wild-type, C57B1/6J mouse is shown in Figure $1, A, B$. Contrast this image with the cerebellum with a $+/ L c$ mutant shown in Figure 1, $G, H$, where comparatively little laminar organization is observed. The chimeric cerebellum shown in Figure $1 C$ contains approximately $50 \%$ of the wildtype number of Purkinje cells, and, as can be seen in this figure, it is reduced in cross-sectional area compared with the control (Fig. 1A). The cytoarchitecture of the chimeric cerebellum is normal, even though it is apparent that there are cells missing from the Purkinje cell layer (Fig. $1 D$ ). One chimera that we examined contained only a small fraction of the number of wildtype Purkinje cells $\left(\chi^{183} ;\right.$ Fig. $\left.1 E\right)$. Despite a significant reduction in size, the laminar organization of its cerebellar cortex is preserved (Fig. $1 F$ ).

\section{Quantitative measurements}

In their study of numerical matching in $+/ L c$ chimeras, Wetts and Herrup (1983) analyzed Purkinje and granule cell numbers in 4 different strains of inbred mice and $4+/ L c$ chimeras. In this study, we have analyzed an additional $5+/ L c$ chimeras, as well as 4 wild-type $\leftrightarrow$ wild-type chimeras (wild-type chimeras). The genotype and the numbers of Purkinje and granule cells for $+/ L c$ chimeric mice and "control" mice (inbred strains and wild-type chimeras) are shown in Table 1 .

As described by Wetts and Herrup (1983), and confirmed by this study, the number of granule cells in both control and $+/ L C$ chimeras is positively correlated with the number of Purkinje cells. Furthermore, in agreement with this earlier study, the ratio of granule cells to Purkinje cells in the $+/ L c$ chimeras is increased over wild-type ratios. A graph of granule cell number
Table 1. Numbers of Purkinje cells and granule cells in each half cerebellum of $+/ L c \leftrightarrow$ wild-type chimeric mice and control mice

$\begin{array}{lllll} & \text { Total no. } & \begin{array}{l}\text { Total no. } \\ \text { GCs } \\ \left(\times 10^{6}\right)\end{array} & \begin{array}{l}\text { PCs } \\ \left(\times 10^{3}\right)\end{array} & \begin{array}{l}\text { GC/PC } \\ \text { ratio }\end{array}\end{array}$

C57BL $/ 6 \mathrm{~J}-+/ L c \leftrightarrow$ wild-type chimeras

\begin{tabular}{|c|c|c|c|c|}
\hline & & & & \\
\hline$\chi^{183 R}$ & $\mathrm{C} 3 \mathrm{H} / \mathrm{HEJ}$ & 3.16 & 4.72 & 669 \\
\hline$\chi^{183 \mathrm{~L}}$ & & 2.38 & 2.37 & 1004 \\
\hline$\chi^{152 R}$ & $\mathrm{C} 3 \mathrm{H} / \mathrm{HEJ}$ & 12.22 & 31.56 & 387 \\
\hline$\chi^{152 L}$ & & 12.43 & 42.87 & 290 \\
\hline$\chi^{154 R}$ & AKR/J & 14.68 & 47.38 & 310 \\
\hline$\chi^{154 L}$ & & 16.81 & 63.70 & 263 \\
\hline$\chi^{15 S R}$ & AKR/J & 15.90 & 61.44 & 259 \\
\hline$\chi^{188 \mathrm{R}}$ & $\mathrm{C} 3 \mathrm{H} / \mathrm{HEJ}$ & 19.30 & 85.55 & 225 \\
\hline$\chi^{188 \mathrm{~L}}$ & & 17.83 & 63.41 & 282 \\
\hline$x^{11 a}$ & $\mathrm{C} 3 \mathrm{H} / \mathrm{HEJ}$ & 8.39 & 10.21 & 822 \\
\hline$\chi^{7 a}$ & $\mathrm{C} 3 \mathrm{H} / \mathrm{HEJ}$ & 11.54 & 30.19 & 382 \\
\hline$\chi^{13 a}$ & $\mathrm{C} 3 \mathrm{H} / \mathrm{HEJ}$ & 16.94 & 60.27 & 281 \\
\hline$\chi^{19 a}$ & AKC3 & 20.46 & 101.84 & 201 \\
\hline \multicolumn{5}{|c|}{ Control $\mathrm{C} 57 \mathrm{BL} / 6 \mathrm{~J}+/+\leftrightarrow+/+$ chimeras } \\
\hline$\chi^{157}$ & $\mathrm{AKR} / \mathrm{J}$ & 16.6 & 84.86 & 196 \\
\hline$\chi^{153 \mathrm{R}}$ & $\mathrm{C} 3 \mathrm{H} / \mathrm{HEJ}$ & 16.6 & 94.60 & 175 \\
\hline$x^{153 L}$ & & 17.1 & 92.80 & 185 \\
\hline$\chi^{169}$ & AKR/J & 19.8 & 98.56 & 201 \\
\hline$\chi^{170}$ & $\mathrm{AKR} / \mathrm{J}$ & 16.6 & 87.03 & 191 \\
\hline \multicolumn{5}{|c|}{ ontrol inbred mice } \\
\hline & $\mathrm{Ic} / \mathrm{Le}^{a}$ & 11.7 & 68.59 & 171 \\
\hline & $\mathrm{C} 3 \mathrm{H} / \mathrm{HEJ}^{a}$ & 15.4 & 83.88 & 183 \\
\hline & $\mathrm{C} 57 \mathrm{Bl} / 6 \mathrm{~J}^{a}$ & 17.8 & 93.91 & 190 \\
\hline & $\mathrm{AKC}^{a}$ & 19.5 & 113.85 & 171 \\
\hline \multicolumn{5}{|c|}{ urcher mutant mice $(\mathrm{C} 57 \mathrm{Bl} / 6 \mathrm{~J}-+/ L c)$} \\
\hline & $+/ L c^{a}$ & 1.6 & 0 & - \\
\hline & $+/ L c^{a}$ & 1.2 & 0 & - \\
\hline & $+/ L \mathcal{C}^{a}$ & 1.5 & 0 & - \\
\hline
\end{tabular}

${ }^{a}$ Data for these animals taken from Wetts and Herrup (1983).

versus Purkinje cell number for $+/ L c$ chimeras and "control" animals is shown in Figure 2. The data points for the control mice are well fit by a straight line linear-regression equation. The regression equation for the control mice has a correlation coefficient $\left(R^{2}\right)$ equal to 0.83 , a slope of $0.176( \pm 0.03)$, and a $y$-intercept of $0.76( \pm 2.84)$ million granule cells. The $y$-intercept is not significantly different from zero, indicating that there is a strict linear numerical matching between granule cells and Purkinje cells in "control" animals: a $y$-intercept of zero implies that if all of the Purkinje cells were removed, granule cell number would be reduced to zero. The data points for the lurcher chimeras can be fit reasonably well by either a curvilinear-regression equation or by a linear-regression equation. The curvilinear-regression equation has a $R^{2}$ value of 0.96 and has the following form: $G=2.84+0.32 P-\left(1.42 \times 10^{-3}\right) P^{2}$, where $G$ is the number of granule cells and $P$ is the number of Purkinje cells. The linear least-squares equation has a $R^{2}$ value of 0.91 ,

Figure 1. Photomicrographs of sagittal sections of the cerebellum at low magnification and the Purkinje and granule cell layer at high magnification from an inbred mouse $(A, B)$, a chimera with $50 \%$ of the wild-type number of Purkinje cells ( $\chi^{154}$ right: $C, D$ ), a second chimera with only a small fraction of the normal number of Purkinje cells $\left(\chi^{183}: E, F\right)$, and a lurcher mutant $(G, H)$. Scale bars for the sagittal cerebellar views, 0.2 mm; for the Purkinje and granule cell layers, $20 \mu \mathrm{m}$. 


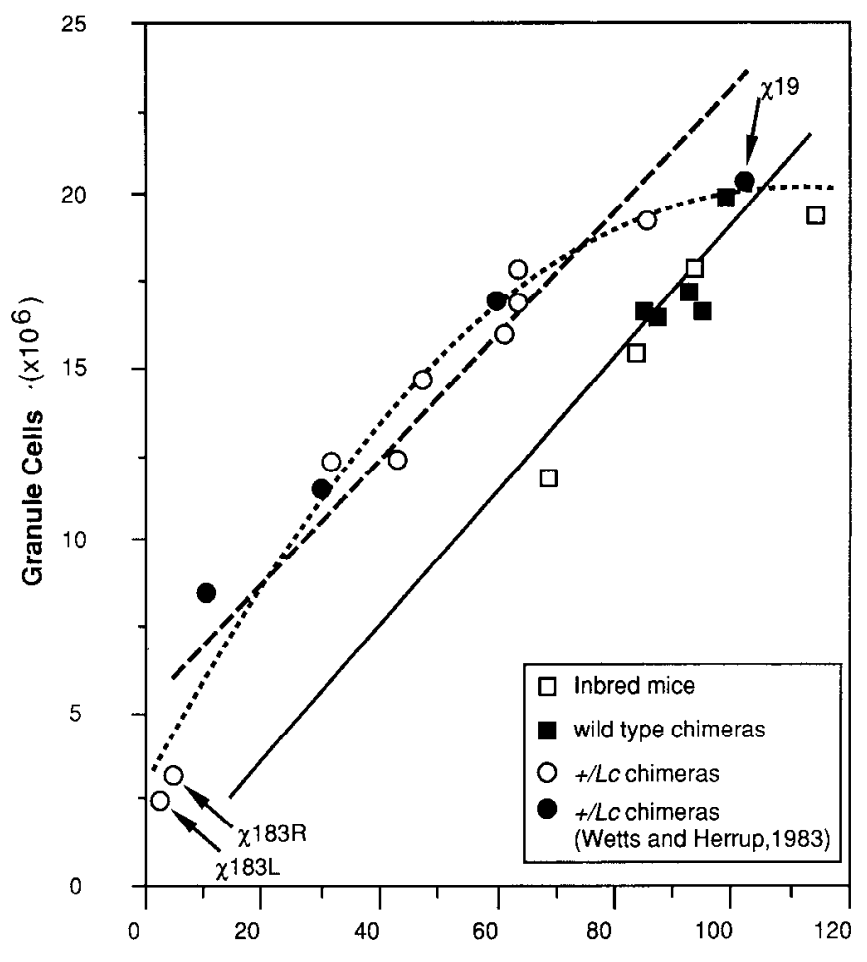

Purkinje Cells $\left(\times 10^{3}\right)$

Figure 2. Total number of granule cells versus Purkinje cells in each half cerebellum from control inbred mice strains (Ic/Le, C3H/HeJ, $\mathrm{C} 57 \mathrm{BL} / 6 \mathrm{~J}$, and $\mathrm{AKC} 3$ ), wild-type $\leftrightarrow$ wild-type chimeras, and $+/ L c \leftrightarrow$ wild-type chimeras. $+/ L c$ chimeras that were originally reported by Wetts and Herrup (1983) are represented by filled circles and $+/ L c$ chimeras analyzed for this study are represented by open circles. Inbred mice originally reported by Wetts and Herrup (1983) are represented by open squares, while wild-type $\leftrightarrow$ wild-type chimeras are represented by filled squares. The solid line represents the linear control matching relationship, the dashed line represents the linear lurcher chimera matching relationship, and the dotted line represents the curvilinear lurcher chimera matching relationship. All 3 lines were fitted according to a least-squares regression equation. The 2 chimeras $\chi^{183}$ and $\chi^{19}$ with questionable genotypes are indicated. If both animals are considered as $+/ L c$ chimeras, then the Purkinje:granule cell relationship can be fit with either a linear $\left(R^{2}=0.91\right)$ or curvilinear $\left(R^{2}=0.96\right)$ regression equation. If both animals are removed from the analysis because of the ambiguity of their genetic identities, then the $+/ L c$ chimeric Purkinje: granule relationship is best described by a linear-regression equation $\left(R^{2}=0.96\right)$.

a slope of $0.179( \pm 0.02)$, and a $y$-intercept of $4.88( \pm 0.95)$ million granule cells.

For a given number of Purkinje cells, the $+/ L c$ chimera granule cell values are significantly higher than the "control"' granule cell values. When experimental treatment $(+/ L c$ chimera or control animal) is included in the regression model, it is a significant variable $(p<0.01, t$ test), indicating that the $+/ L c$ chimera or control data sets are best described by separate regression equations. Furthermore, the offset of the $+/ L c$ chimera numerical matching relationship above the control relationship cannot simply be explained as the control relationship plus the number of granule cells that survive in the $+/ L c$ mutant. Although approximately one and a half million granule cells survive in the $+/ L c$ mutant (Table 1), the number of granule cells in the chimeras exceeds that expected in control animals

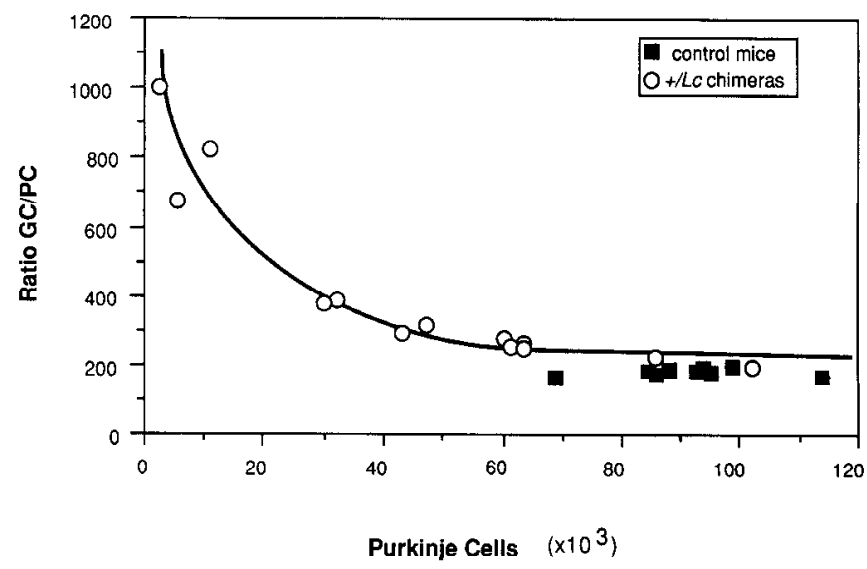

Figure 3. Ratio of granule to Purkinje cell numbers for the hemicerebella of control mice (inbred strains and wild-type chimeras) and lurcher mice plotted against the total number of Purkinje cells per hemicerebella. Control animals are represented by filled squares, while lurcher chimeras are represented by open circles. The curve for the chimeric data points was fitted by eye.

with a comparable number of Purkinje cells by at least 3 times the number of granule cells that survive in the $1 / L c$ mutant.

In the linear least-squares equation for the $+/ L c$ chimeras, we discovered that 2 of the $+/ L c$ chimeras, $\chi^{183}$ and $\chi^{19}$, have much larger residual values in the regression analysis of the Purkinje and granule cell data than the other chimeras. These 2 animals are unusual in several respects. First, they represent the low and high ends in the range of Purkinje cell numbers found in the $+/ L c$ chimeras, and this may have an effect on granule cell survival. Second, there is some ambiguity about the genotypes of these animals, and the effect that their genotype may have on the number of granule and Purkinje cells is not known.

$\chi^{183}$ was initially identified as a chimera on the basis of progeny testing (10 of 21 progeny were $+/ L c$ mutants) and on the basis of having fewer than a wild-type number of surviving Purkinje cells. All of the remaining Purkinje cells were presumed to be of the $\mathrm{C} 3 \mathrm{H} / \mathrm{HeJ}$ genotype. However, $\chi^{183}$ was constructed from one $\mathrm{C} 3 \mathrm{H} / \mathrm{HeJ}$ embryo and one $\mathrm{C} 3 \mathrm{~B} 6(\mathrm{~F} 1)-+/ L c$ embryo. Thus, any $+/ L c$ mutant cells in this chimera would have a hybrid genetic background. If the lurcher gene has incomplete penetrance when expressed on a C3B6 background, the result might be that not all of the $+/ L c$ Purkinje cells degenerate. Further, $\beta$-glucuronidase staining of Purkinje cells in C3B6 mice is not as reliable as in $\mathrm{C} 57 \mathrm{BL} / 6$ since the cells are heterozygous for the low- and high-staining $\beta$-glucuronidase alleles.

Different concerns can be raised about $\chi^{19}$. The strain of the wild-type embryo used to construct this chimera was AKC3 $\left(\mathrm{F}_{2}\right)$, while the mutant embryo was obtained from heterozygous matings of a $C 57 \mathrm{Bl} / 6 \mathrm{~J}-+/ L c$ mutant mouse with a $C 57 \mathrm{Bl} / 6 \mathrm{~J}-$ $+/+$ inbred mouse. The animal was identified as a chimera in the original study (Wetts and Herrup, 1983) on the basis of its coat color chimerism ( $80 \%$ albino $/ 20 \%$ black) and on the fact that all of the Purkinje cells were low staining for $\beta$-glucuronidase [indicating that they were descended from the AKC3 $\left(\mathrm{F}_{2}\right)$ embryo (unpublished observations)]. This animal was not successfully progeny tested, however, and the possibility exists that, although this animal is chimeric in most cell types, the progenitors of the Purkinje cells were all descended from the AKC3 $\left(F_{2}\right)$ embryo. The genotype of the C57BL/6 embryo could then 
have been $+/ t$, and not $+/ L c$, as originally assumed. In this case, the granule cell to Purkinje cell relationship should have been the same as in control animals, and this is what was observed. None of the other chimeras included in this study had any irregularities or uncertainties in their background or progeny testing.

If these 2 chimeras, $\chi^{183}$ and $\chi^{19}$, are omitted from the data set because of the uncertainty in classifying them as either true $+/ L c$ chimeras or controls, the $+/ L c$ chimeric data points are less adequately described by a quadratic regression equation: the coefficient of the $P^{2}$ term becomes $-3.9 \times 10^{-4}$, which is no longer significantly different from zero ( $p>0.4, t$ test). This suggests that the $+/ L c$ chimera points are best described by a linear-regression equation, although the certainty of this conclusion must be tempered somewhat by the fact that, without $\chi^{183}$ and $\chi^{19}$, our data do not sample the high and low regions of the curve. The linear regression equation for the $+/ L c$ chimeras without $\chi^{183}$ and $\chi^{19}$ has a $R^{2}$ value of 0.96 and a slope of $0.152( \pm 0.01)$, and the $y$-intercept of the $+/ L c$ chimera regression equation is changed from $4.88( \pm 0.95)$ to $7.03( \pm 0.60)$ million granule cells. The slopes of the linear equations for the control and $+/ L c$ chimera groups are different, but not significantly ( $p>0.05, t$ test), while the $y$-intercept for the $+/ L c$ chimcra equation is significantly greater than zero $(p<0.001$, $t$ test).

\section{Numerical matching}

The numerical matching ratio for a target population and its presynaptic input can be defined as the ratio of the number of presynaptic neurons to the number of postsynaptic, target cells. In the case of inbred mice, wild-type - wild-type chimeras, and staggerer chimeras (Herrup and Sunter, 1987), the $y$-intercept is not significantly different from zero, so the numerical matching ratio for Purkinje and granule cells is equivalent to the slope of the least-squares regression equation for the 2 cell types (Fig. $2)$. This is not true of $+/ L c$ chimeras, for which the $y$-intercept is significantly different from zero and the ratio of granule cells to Purkinje cells increases logarithmically as the number of Purkinje cells decreases (Fig. 3). The numerical matching function for Purkinje and granule cells in the $+/ L c$ chimeras is therefore inversely proportional to the number of wild-type Purkinje cells.

\section{Discussion}

The numerical matching hypothesis for target-related cell death predicts that the size of the target should regulate the number of presynaptic neurons. One of the problems in testing this hypothesis has been designing experiments that vary the target size across a wide range of values without affecting the specificity of pre- and postsynaptic innervation. Cerebellar mutant $\leftrightarrow$ wildtype chimeras are largely successful in resolving these problems (Wetts and Herrup, 1983; Herrup and Sunter, 1987). First, the size of the target (Purkinje cell number) can be varied from 0 to over $100 \%$ of average wild-type values in both staggerer and lurcher chimeras. At birth, each chimera is composed of mutant and wild-type Purkinje cells in ratios that vary from animal to animal. Since neither staggerer $(s g / s g)$ nor lurcher $(+/ L c)$ Purkinje cells are available as granule cell targets due to intrinsic genetic defects, each chimera contains a different number of targets for granule cell synaptogenesis (Herrup and Mullen, 1979; Wetts and Herrup, 1982a). Second, the surviving Purkinje cells are scattered throughout the chimeric cerebellum, so there are no specific regions of the cerebellum that are devoid of Purkinje cells (Wetts and Herrup, 1983; Herrup and Sunter, 1987). Finally, the Purkinje cells that remain are untreated by chemical or physical intervention and are genetically wild type. Thus, the mutant $\leftrightarrow$ wild-type chimera provides unique advantages as a model for the analysis of numerical matching in target-related cell death.

The analysis of Purkinje and granule cell numbers in 4 different inbred mouse strains and in staggerer chimeras has shown that there is a simple linear correlation between the number of target Purkinje cells and the number of presynaptic granule cells (Wetts and Herrup, 1983; Herrup and Sunter, 1987). A similar analysis in $+/ L c$ chimeras, however, suggests that the Purkinje cell-granule cell relationship is more complex in these animals. In virtually every animal examined, $\mathrm{a}+/ L c$ chimera had more granule cells per Purkinje cell than would a staggerer chimera with a similar number of wild-type Purkinje cells. Over most of the range of Purkinje cell numbers in the $+/ L c$ chimeras there is a linear relationship between the the number of granule and Purkinje cells. The number of wild-type Purkinje cells in each chimera is dependent on the relative number of wild-type and $+/ L c$ Purkinje cell progenitor cells present in the chimeric embryo (Wetts and Herrup, 1982c). The close correlation between the number of granule and Purkinje cells in the $+/ L c$ chimeras suggests that the size of the granule cell population is largely dependent on the size of the Purkinje cell population. However, whereas the ratio of granule cells to Purkinje cells is constant in the inbred strains and staggerer chimeras, in the $+/ L c$ chimeras, the granule to Purkinje cell ratio increases as the number of wild-type Purkinje cells declines (see Fig. 3).

What are the differences between the 2 mutant chimeras that can explain this finding? In both mutants, the Purkinje cell is a primary site of gene action, while the granule cell is not (Wetts and Herrup, 1982a, b; Herrup, 1983). It seems unlikely that the differences are due to a second, as yet unidentified, primary site of lurcher gene action. All of the known phenotypes of both mutants can be explained solely on the basis of the Purkinje cell defect. Further, if this second site of gene action did exist and some aspect of the lurcher mutation allowed increased granule cell survival in the chimeric environment, then the extent of this increase would be expected to diminish as the ratio of genotypes in the chimeras approached $100 \%$ wild type. For example, if the lurcher mutation altered the trophic requirements of granule cells to allow increased survival of $+L c$ granule cells, then the increased survival of granule cells in $+/ L c$ chimeras would be expected to decrease as the percent chimerism approached $100 \%$ wild type. This would appear to be contrary to the observed data showing several points in which the number of Purkinje cells is nearly normal (i.e., the percentage of lurcher in the chimera is very low) yet the granule cell number is still above that predicted by the "control" line of staggerer chimeras and wild-type mice.

The salient feature that does differentiate between staggerer and $+/ L c$ chimeras is the availability of mutant Purkinje cells for target interactions. In staggerer chimeras, staggerer Purkinje cells are intrinsically deficient and are therefore never available for synaptic interactions with granule cells (Herrup and Mullen, 1979). In contrast, in the $+/ L c$ mutant, $+/ L c$ Purkinje cells do not begin to degenerate until after the first week of granule cell histogenesis (Caddy and Biscoe, 1979). Granule cells initiate contacts with target Purkinje cells soon after they are generated (Landis and Sidman, 1978), and since $+/ L c$ Purkinje cells are capable of forming synapses with granule cells (K W. T. Caddy, 
personal communication), it seems likely that the transient presence of $+/ L c$ Purkinje cells in $+/ L c$ chimeras is the factor that alters granule cell survival in $+/ L c$ chimeras. A majority of the granule cells that survive in the $+/ L c$ mutant were generated prior to $+/ L c$ Purkinje cell degeneration and were presumably stabilized by initial contacts with $+/ L c$ Purkinje cells (Vogel and Herrup, 1989). This suggests that $+/ L c$ Purkinje cells can interact with granule cells prior to their degeneration.

There are at least 4 hypotheses that may explain the increased survival of granule cells in $+/ L c$ chimeras that are all based on the assumption that the critical difference between $+/ L c$ and staggerer chimeras is the transient presence of a population of $+/ L c$ Purkinje cells in $+/ L c$ chimeras. First, while the site of mutant gene action may be unchanged in the chimeras, the timing of gene action may be altered in the $+/ L c$ chimera. Second, the death of the $+/ L c$ Purkinje cells in the chimeric environment may alter granule cell survival requirements to allow increased granule cell survival. Third, $+/ L c$ Purkinje cell degeneration may affect an unidentified population of cells that have an influence on granule survival. Fourth, the death of the $+/$ Lc Purkinje cells may alter the capacity of the remaining wild-type Purkinje cells to support granule cell survival.

We believe that the first hypothesis can be excluded on the basis of the observed data. Specifically, the hypothesis is that while death and degeneration may be the unalterable fate of any $+/ L c$ Purkinje cell, the timing of this cell death might be different in the chimeric environment. A delay in $+/ L c$ Purkinje cell degeneration in the chimera might allow increased granule cell survival because the mutant Purkinje cells would be present longer and offer increased developmental stabilization. Counts of the adult number of Purkinje cells may underestimate the number of effective Purkinje cell targets at the time when cell death decisions are made. However, if timing explained the differences between the staggerer and lurcher chimeras, then, as discussed above, this phenotype should depend on the degree of chimerism. As the ratio of genotypes approached $100 \%$ wild type, the delay in the death of the lurcher Purkinje cells should be greatest; hence the deviation from the wild-type granule to Purkinje cell ratio should be the greatest. Conversely, as the chimera genotype ratio approached $100 \%$ lurcher, the delay in the $+/ L c$ Purkinje cell degeneration should be the least and the granule to Purkinje cell ratio should be closer to wild-type values. Neither of these predicted situations is supported by our data. This hypothesis can also be excluded on a second ground: if timing were indeed the sole explanation for the survival of supernumerary granule cells, then it would be predicted that the granule cells born earlier in the development (and having a longer access to their Purkinje cell target) would be more likely to survive in the lurcher chimera than those born late in the period of granule cell genesis. Recent tritiated thymidine birthdate studies of granule cell survival (Vogel and Herrup, 1989) have shown that this is not the case. The tritiated thymidine birthdate labeling data also do not support the original hypothesis suggested by Wetts and Herrup (1983) that the increased granule cell survival in $+/ L c$ chimeras is due to the preferential survival of granule cells generated prior to the death of $+/ L C$ Purkinje cells. Rather, the birthdate labeling data indicates that it is unlikely that the increased number of surviving granule cells in $+/ L c$ chimeras is due to a population of granule cells that are "rescued" by benefit of target interactions with $+/ L C$ Purkinje cells prior to their intrinsic degeneration.
The second hypothesis that the transient presence of $+/ L c$ Purkinje cells alters the survival requirements of granule cells cannot be similarly ruled out. One possibility is that granule cell survival requirements following induced target cell death (i.e., following $+/ L c$ Purkinje cell degeneration) may be different from survival requirements during naturally occurring cell death (i.e., in inbred mouse strains or in staggerer chimeras where the only available target cells are all wild type). If this were the case, then granule cell survival in $+/ L c$ chimeras would not necessarily by expected to be similar to that in staggerer chimeras. One constraint on this hypothesis, however, is that tritiated thymidine birthdate labeling studies of $+/ L c$ chimcras have shown that granule cells generated after $+/ L c$ Purkinje cell degeneration do not survive preferentially (Vogel and Herrup, 1989). This implies that $+/ L c$ Purkinje cell degeneration would have to have an equivalent effect on granule cells generated before and after the period of $+/ L c$ Purkinje cell degeneration.

With respect to the third hypothesis that there is an unidentified cell type in $+/ L c$ chimeras that may alter granule cell survival, afferent input has been shown to affect neuron survival during naturally occurring cell death (see Okado and Oppenheim, 1984; Furber et al., 1987); afferent inputs to granule cells may similarly stabilize some granule cells in the $+/ L c$ chimera. However, the good correlation between the number of Purkinje cells and granule cells in $+/ L c$ chimeras suggests that it may not be necessary to hypothesize the existence of a third, unidentified cell type that plays a major role in regulating granule cell survival in $+/ L c$ chimeras. Nevertheless, we cannot rule out the possibility that there are other variables besides target size that may play a role in regulating the number of presynaptic neurons (e.g., see Sperry, 1988).

We believe that there are compelling reasons for preferring the fourth hypothesis, that wild-type Purkinje cells are altered by the death of $+/ L c$ Purkinje cells, albeit indirectly. Specifically, we propose that the increased ratio of granule to Purkinje cells observed in the lurcher chimeras is a granule cell response to the deafferentation of their Purkinje cell target. In vivo and in vitro studies have shown that denervation causes normal muscles to increase their release of a trophic factor that enhances motor neuron survival (Slack and Pockett, 1982; Nurcombe et al., 1984; Dohrmann et al., 1986; Haverkamp et al., 1987; Oppenheim et al., 1988). By analogy to the neuromuscular system, we propose that wild-type Purkinje cells in the lurcher chimera are deafferented during the course of cerebellar development and, in response, release a trophic influence that allows for increased granule cell survival.

Evidence that Purkinje cell deafferentation occurs in lurcher chimeras comes from Golgi-Cox studies of wild-type Purkinje cells (Caddy et al., 1986). The dendritic arbors of these wildtype Purkinje cells are reduced in size and spread out in the sagittal plane. In addition, their branching complexity is reduced, there are many examples of dendrites with unbranched segments (unusual for Purkinje cells), and there are frequent images of large caliber dendrites ending abuptly in what $\mathrm{K}$. W. T. Caddy and K. Herrup (unpublished observations) have termed "stub ends." All of these changes are hallmarks of deafferented dendrites. The Purkinje cell dendrites in the lurcher chimeras strongly resemble those described by Altman (1973) in his study of Purkinje cell morphology in rat cerebella with disoriented parallel fibers. Our interpretation of his results is that the abnormally oriented parallel fibers cannot make correct synapses 
with Purkinje cells, and therefore, Purkinje cells (near the site of the $\mathrm{x}$-irradiation lesion and the sagittally oriented parallel fibers) are deafferented.

We propose that granule cells are dependent on Purkinje cell targets for stabilization during a "critical period" of granule cell development (see the excellent discussion by Sidman, 1977; see also Vogel and Herrup, 1989). According to this hypothesis, a granule cell is dependent for target stabilization on some subset of the Purkinje cells it contacts. Granule cells extend parallel fibers for millimeters in the molecular layer, and since both $+/ L c$ and wild-type Purkinje cells are intermixed in the chimeric cerebellum, each granule cell most likcly contacts both $+/ L c$ and wild-type Purkinje cells. The mix of $+/ L c$ and wild-type Purkinje cells that a granule cell contacts will vary with the overall ratio of genotypes in the chimera. The degeneration of $+/ L c$ Purkinje cells will decrease the overall size of the target and some proportion of the granule cell population will also die. Any wild-type Purkinje cell that has contacts with dying granule cells will lose parallel fiber inputs and will be partially deafferented.

The prediction is that there should be an inverse relationship between the number of wild-type Purkinje cells in a chimera and the ratio of granule cells to Purkinje cells. The fewer wildtype Purkinje cells there are in the adult chimera, the more $+/ L c$ Purkinje cells there must have been in the neonatal chimera. As the number of wild-type Purkinje cells in a series of chimeras decreases, the extent of granule cell death must increase. Consequently, deafferentation becomes more severe as the number of $+/+$ Purkinje cells decreases and the deafferentation response increases. Evidence that this occurs can be found in the increasing granule to Purkinje cell ratios (see Fig. 3 ). Work is currently in progress to test this hypothesis by attempting to correlate the number of Purkinje cells in a chimera with the severity of Purkinje cell dendritic abnormalities. A second, critical test is to determine whether wild-type Purkinje cells in staggerer chimeras have a disrupted morphology as in $+/ L c$ chimeras, and this study is also in progress.

\section{References}

Altman, J. (1973) Experimental reorganization of the cerebellar cortex. IV. Parallel fiber reorientation following regeneration of the external germinal layer. J. Comp. Neurol. 149: 181-192.

Berenson, M. L., D. M. Levine, and M. Goldstein (1983) Intermediate Statistical Methods and Applications, pp. 326-364, Prentice-Hall, Englewood Cliffs, N.J.

Boydston, W. R., and G. S. Sohal (1979) Grafting of additional periphery reduces embryonic loss of neurons. Brain Res. 178: 403-410.

Caddy, K. W. T., and T. J. Biscoe (1979) Structural and quantitative studies on the normal $\mathrm{C} 3 \mathrm{H}$ and Lurcher mutant mouse. Phil. Trans. R. Soc. London [Biol.] 287: 167-201.

Caddy, K. W. T., G. Fieldman, and K. Herrup (1986) Quantitative analysis of Purkinje cell dendrites in normal and Lurcher chimeric mice. Soc. Neurosci. Abstr. 12: 1583.

Cowan, W. M., J. W. Fawcett, D. D. M. O'Leary, and B. B. Stanfield (1984) Regressive events in neurogenesis. Science 225: 1258-1265.

Denton, C. L., A. H. Lamb, P. Wilson, and R. F. Mark. (1985) Innervation pattern of muscles of one-legged Xenopus laevis supplied by motoneurons from both sides of the spinal cord. Dev. Brain Res. 17: 85-94.

Dohrmann, U., D. Edgar, M. Sendtner, and H. Thoenen (1986) Muscle-derived factors that support survival and promote fiber outgrowth from embryonic chick spinal motor neurons in culture. Dev. Biol. 118: 209-221.

Furber, S., R.W. Oppenheim, and D. Prevette (1987) Naturally-occurring neuron death in the ciliary ganglion of the chick embryo following removal of preganglionic input: Evidence for the role of afferents in ganglion cell survival. J. Neurosci. 7: 1816-1832.

Haverkamp, L. J., R. W. Oppenheim, S. H. Appel, D. Prevette, and J. L. McManaman (1987) Reduction of naturally occurring motoneuron death by sera from patients with denervating disease. Soc. Neurosci. Abstr. 13: 923.

Hendry, I. A. (1976) A method to correct adequately for the change in neuronal size when estimating neuronal numbers following nerve growth factor treatment. J. Neurocytol. 5: 337-349.

Herrup, K. (1983) Role of staggerer gene in determining cell number in cerebellar cortex. I. Granule cell death is an indirect consequence of staggerer gene action. Dev. Brain Res. 11: 267-274.

Herrup, K., and R. Mullen (1979) Staggerer chimeras: Intrinsic nature of Purkinje cell defects and implications for normal cerebellar development. Brain Res. 178: 443-457.

Herrup, K., and K. Sunter (1987) Granule cell death during cerebellar development of staggerer mouse chimeras: A test of the numerical matching hypothesis. J. Neurosci. 7: 829-836.

Hollyday, M., and V. Hamburger (1976) Reduction of the naturally occurring motor neuron loss by enlargement of the periphery. J. Comp. Neurol. 170: 311-320.

Lamb, A. (1979) Evidence that some developing limb motoneurons die for reasons other than peripheral competition. Dev. Biol. 71: 821 .

Lamb, A. (1981) Selective bilateral motor innervation in Xenopus tadpoles with one hind limb. J. Embryol. Exp. Morphol. 65: 149163.

I amb, A. H. (1984) Motoneuron death in the embryo. Crit. Rev. Clin. Neurobiol. 1: 141-179.

Landis, D. M. D., and R. L. Sidman (1978) Electron microscopic analysis of postnatal histogenesis in the cerebellar cortex of staggerer mutant mice. J. Comp. Neurol. 179: 831-863.

Lanser, M. E., and J. F. Fallon (1987) Development of the brachial lateral motor column in the wingless mutant chick embryo: Motoneuron survival under varying degrees of peripheral load. J. Comp. Neurol. 261: 423-434.

Mintz, B. (1965) Genetic mosaicism in adult mice of quadriparental lineage. Science 148: 1232-1233.

Mullen, R. J., and W. K. Whitten (1971) Relationships of genotypes and degree of chimerism in coat color to sex ratios and gametogenesis in chimeric mice. J. Exp. Zool. 178: 165-176.

Narayanan, C. H., and Y. Narayanan (1978) Neuronal adjustments in developing nuclear centers of the chick embryo following transplantation of an additional optic primordium. J. Embryol. Exp. Morphol. 44: 53-70.

Nurcombe, V., M. A. Hill, K. L. Eagleson, and M. R. Bennett (1984) Motor neuron survival and neuritic extension from spinal cord explants induced by factors released from denervated muscle. Brain Res. 291: 19-28.

Okado, N., and R. W. Oppenheim (1984) Cell death of motoneurons in the chick embryo. IX. The loss of motoneurons following removal of afferent inputs. J. Neurosci. 4: 1639-1652.

O'Leary, D. D. M., and W. M. Cowan (1982) Further studies on the development of the isthmooptic nucleus with special reference to the occurrence and fate of ectopic and ipsilaterally projecting neurons. J. Comp. Neurol. 212: 399-416.

Oppenheim, R. W. (1985) Naturally occurring cell death during neural development. Trends Neurosci. 8: 487-493.

Oppenheim, R. W., L. J. Haverkamp, D. Prevette, J. L. McManaman, and S. H. Appel (1988) Reduction of naturally occurring motoneuron death in vivo by a target-derived neurotrophic factor. Science 240: 919-922.

Phillips, R. J. S. (1960) "Lurcher," a new gene in linkage group XI of the house mouse. J. Genet. 57: 35-42.

Pilar, G. L., L. T. Landmesser, and L. Burstein (1980) Competition for survival among developing ciliary ganglion cells. J. Neurophysiol. 43: 233-254.

Sidman, R. L. (1977) Experimental neurogenetics. In Genetics of Neurological Disorders, R. L. Sidman and S. W. Matthysse, eds., pp. 1946, Raven, New York.

Slack, J. R., and S. Pockett (1982) Motor neurotrophic factor in denervated adult skeletal muscle. Brain Res. 247: 138-140.

Sohal, G. S., S. D. Stoney, Jr., T. Arumugam, T. Yamashita, and T. S. Knox (1986) Influence of reduced neuron pool on the magnitude of 
naturally occurring motor neuron death. J. Comp. Neurol. 247: 516528.

Sperry, D. G. (1988) Effects of increasing ploidy on the lumbar lateral motor column and hindlimb of newly metamorphosed Xenopus laevis: A comparison of diploid and triploid siblings. J. Comp. Neurol. 277: 499-508.

Tanaka, H., and L. T. Landmesser (1986) Cell death of lumbosacral motoneurons in the chick, quail, and chick-quail chimera embryos: A test of the quantitative matching hypothesis of neuronal cell death. J. Neurosci. 6: 2889-2899.

Tarkowski, A. K. (1961) Mouse chimeras developed from fused eggs. Nature 190: 357-360.

Vogel, M. W., and K. Herrup (1989) Numerical matching in the mammalian CNS: Lack of a competitive advantage of early over late generated cerebellar granule cells. J. Comp. Neurol. (in press).

Vogel, M. W., K. Sunter, and K. Herrup (1987) Cell death in the developing mouse cerebellum: Further studies of numerical matching between Purkinje and granule cells in $+/$ Lc chimeras. Soc. Neurosci. Abstr. 13: 923.
Wetts, $R$, and K. Herrup (1982a) Interaction of granule, Purkinje and inferior olivary neurons in lurcher chimeric mice. I. Qualitative studies. J. Embryol. Exp. Morphol. 68: 87-98.

Wetts, R., and K. Herrup (1982b) Interaction of granule, Purkinje and inferior olivary neurons in lurcher chimeric mice. II. Granule cell death. Brain Res. 250: 358-363.

Wetts, R., and K. Herrup (1982c) Cerebellar Purkinje cells are descended from a small number of progenitors committed during early development: Quantitative analysis of lurcher chimeric mice. J. Neurosci. 2: 1494-1498.

Wetts, R., and K. Herrup (1983) Direct correlation between Purkinje and granule cell number in the cerebella of lurcher chimeras and wildtype mice. Dev. Brain Res. 10:41-47.

Williams, R. W., and K. Herrup (1988) The control of neuron number. Annu. Kev. Neurosci. 11: 423-453. 